\title{
PALINOLOGIA DO MORRO DO PAPALÉO, MARIANA PIMENTEL (PERMIANO INFERIOR, BACIA DO PARANÁ), RIO GRANDE DO SUL, BRASIL
}

\author{
LARISSA P. SMANIOTTO, TIAGO V. FISCHER, PAULO A. SOUZA \& ROBERTO IANNUZZI \\ Departamento de Paleontologia e Estratigrafia, Instituto de Geociências, UFRGS, Av. Bento Gonçalves, 9500, 91540-000, Porto Alegre, \\ RS, Brasil.lari_paludo@yahoo.com.br,fischer.tiago@gmail.com,paulo.alves.souza@ufrgs.br, roberto.iannuzzi@ufrgs.br
}

\begin{abstract}
RESUMO - Este trabalho apresenta os resultados da análise palinológica de níveis do Subgrupo Itararé e da Formação Rio Bonito na localidade do Morro do Papaléo, município de Mariana Pimentel, Rio Grande do Sul. As palinofloras registradas são relativamente abundantes e diversificadas, tendo sido identificadas 20 espécies de esporos, 13 de grãos de pólen, 5 de espécies microplânctonicas, além de táxons atribuídos a fungos. Dentre os esporomorfos, 3 espécies são inéditas para a porção brasileira da bacia do Paraná: Horriditriletes gondwanensis (Tiwari \& Moiz) Foster, Horriditriletes superbus (Foster) Césari, Archangelsky \& Seoane e Brazilea helby forma gregata Foster. As palinofloras correspondem à Subzona Protohaploxypinus goraiensis, base da Zona Vittatina costabilis, pela presença de espécies diagnósticas (Protohaploxypinus goraiensis, P. limpidus e Illinites unicus), com posicionamento na base do Permiano (Asseliano/Sakmariano). A presença de espécies microplanctônicas (Brazilea, Leiosphaeridia, Quadrisporites e Tetraporina), que ocorrem de forma diferenciada em ambas as unidades, bem como as relações percentuais entre os grupos da matéria orgânica particulada permitem a proposição de ambiente marinho raso e/ou transicional com influência marinha para o Subgrupo Itararé e ambiente lacustre e/ou pantanoso para a Formação Rio Bonito, corroborando dados litofaciológicos e paleontológicos prévios.
\end{abstract}

Palavras-chave: Palinologia, Subgrupo Itararé, Formação Rio Bonito, bioestratigrafia, paleoambiente.

\begin{abstract}
PALYNOLOGY OF THE MORRO DO PAPALÉO, MARIANA PIMENTEL (LOWER PERMIAN, PARANÁ BASIN), RIO GRANDE DO SUL, BRAZIL. This paper presents the main palynological results from different levels of the Itararé Subgroup and the Rio Bonito Formation, in the Morro Papaléo outcrop, Mariana Pimentel Municipality, Rio Grande do Sul. Palynofloras recovered are relatively abundant and diversified. Twenty species of spores, thirteen of pollen grains, and five of microplanktonic species, as well as several taxa assigned to fungi were identified. Three sporomorphs are recorded for the first time to the Brazilian Paraná Basin: Horriditriletes gondwanensis (Tiwari \& Moiz) Foster, Horriditriletes superbus (Foster) Césari, Archangelsky \& Seoane and Brazilea helby forma gregata Foster. Based on the presence of guide species (e.g., Protohaploxypinus goraiensis, P. limpidus and Illinites unicus), the palynofloras are attributed to the Protohaploxypinus goraiensis Subzone, base of the Vittatina costabilis Zone, which is considered as Early Permian (Asselian/Sakmarian) in age. The occurrence of microplanktonic species (Brazilea, Leiosphaeridia, Quadrisporites and Tetraporina), which occur indistinctly in both units, as well as quantitative relations between the groups of the particulate organic matter, allow to suggest a shallow marine and/or marine-influenced transitional environment to the Itararé Subgroup and a lacustrine and/or swampy environment to the Rio Bonito Formation, corroborating previous lithofaciological and paleontological results.
\end{abstract}

Key words: Palynology, Itararé Subgroup, Rio Bonito Formation, biostratigraphy, paleoenvironment.

\section{INTRODUÇÃO}

A seqüência sedimentar neopaleozóica da bacia do Paraná é composta por depósitos relacionados ao final da fase glacial que afetou extensivamente o Gondwana, representados pelas rochas sedimentares do Subgrupo Itararé, e por depósitos pós-glaciais vinculados ao progressivo aquecimento climático, representados pelos grupos Guatá e Passa Dois.
Essas unidades fazem parte da "Superseqüência Gondwana I" (Milani, 1997; Milani \& Zalán, 1999), de idade carbonífera tardia (Pensilvaniano) a permiana tardia (Lopingiano), que se distribuem por grande extensão na bacia, desde Goiás ao Rio Grande do Sul (Figura 1), e cujos depósitos chegam a ultrapassar $2.500 \mathrm{~m}$ de espessura. No Estado do Rio Grande do Sul, esse pacote sedimentar é menos espesso e compreende idades do Permiano inicial (Cisulariano) ao tardio 
(Lopingiano). O conteúdo fossilífero desta superseqüência é extremamente rico e abundante, destacando-se a presença de macrofósseis vegetais, invertebrados (moluscos, braquiópodes, insetos, dentre outros), vertebrados e palinomorfos. Dentre estes, os últimos destacam-se pela abundância generalizada na bacia e por oferecer significativa resolução bioestratigráfica.

Os macrofósseis vegetais da mina do Morro do Papaléo são relativamente bem conhecidos (Corrêa da Silva \& Arrondo, 1977; Cazzulo-Klepzig et al., 1980; Burjack et al., 1982; Pasqualini et al., 1986; Guerra-Sommer \& CazzuloKlepzig, 1993; Iannuzzi et al., 2003). No entanto, os dados palinológicos são restritos a citação de nove gêneros (Burjack et al., 1982). Dessa forma, este trabalho objetiva apresentar os estudos realizados nas unidades estratigráficas aflorantes na localidade, relativas à porção superior do Subgrupo Itararé e à base da Formação Rio Bonito, abordando a diversidade palinológica registrada, as relações percentuais entre os grupos da matéria orgânica particulada dispersa e seu significado bioestratigráfico e paleoambiental. Esta contribuição é parte de projeto mais amplo que pretende estabelecer, adicionalmente, o posicionamento estratigráfico das biozonas baseadas em restos vegetais (macro e microfósseis), bem como caracterizar os paleoambientes relacionados do Subgrupo Itararé e da Formação Rio Bonito nos estados do Rio Grande do Sul e Santa Catarina.

\section{CONTEXTO GEOLÓGICO E PALEONTOLÓGICO}

O afloramento do Morro do Papaléo localiza-se a, aproximadamente, $8 \mathrm{~km}$ a oeste do centro do município de Mariana Pimentel, com acesso a partir de Porto Alegre, através da rodovia BR 116 e coordenadas geográficas de latitude $30^{\circ} 18^{\prime} 26,32^{\prime}$ 'S e longitude 5138'29,20”W (Figura 1). Seus depósitos constituíram tema de estudo de diversos autores, com abordagem litofaciológica, estratigráfica, paleoambiental e paleogeográfica, destacando-se os trabalhos de Burjack et al. (1982), Paim et al. (1983), Piccoli et al. (1983) e Pasqualini et al. (1986), além de contribuições inéditas (e.g., Silveira, 2000). Os pacotes sedimentares na localidade são relativos ao Subgrupo Itararé e à Formação Rio Bonito, que perfazem uma espessura mínima de aproximadamente $50 \mathrm{~m}$, jazendo discordantemente sobre rochas graníticas, riolíticas e migmatíticas do embasamento, representadas pelo Grupo Cambaí (Paim et al., 1983).

De acordo com Iannuzzi et al. (2003), que realizaram o detalhamento litofaciológico mais recente para a localidade, siltitos e arenitos finos, por vezes rítmicos, dominam na seção basal do afloramento, representativos do Subgrupo Itararé, com aproximadamente $20 \mathrm{~m}$ de espessura, capeados por um pacote de arenito fino a médio. As litologias da Formação Rio Bonito são constituídas por paraconglomerados e arenitos médios a grossos, com pacotes centimétricos a métricos de pelitos carbonosos e, subordinadamente, ritmitos e arenitos

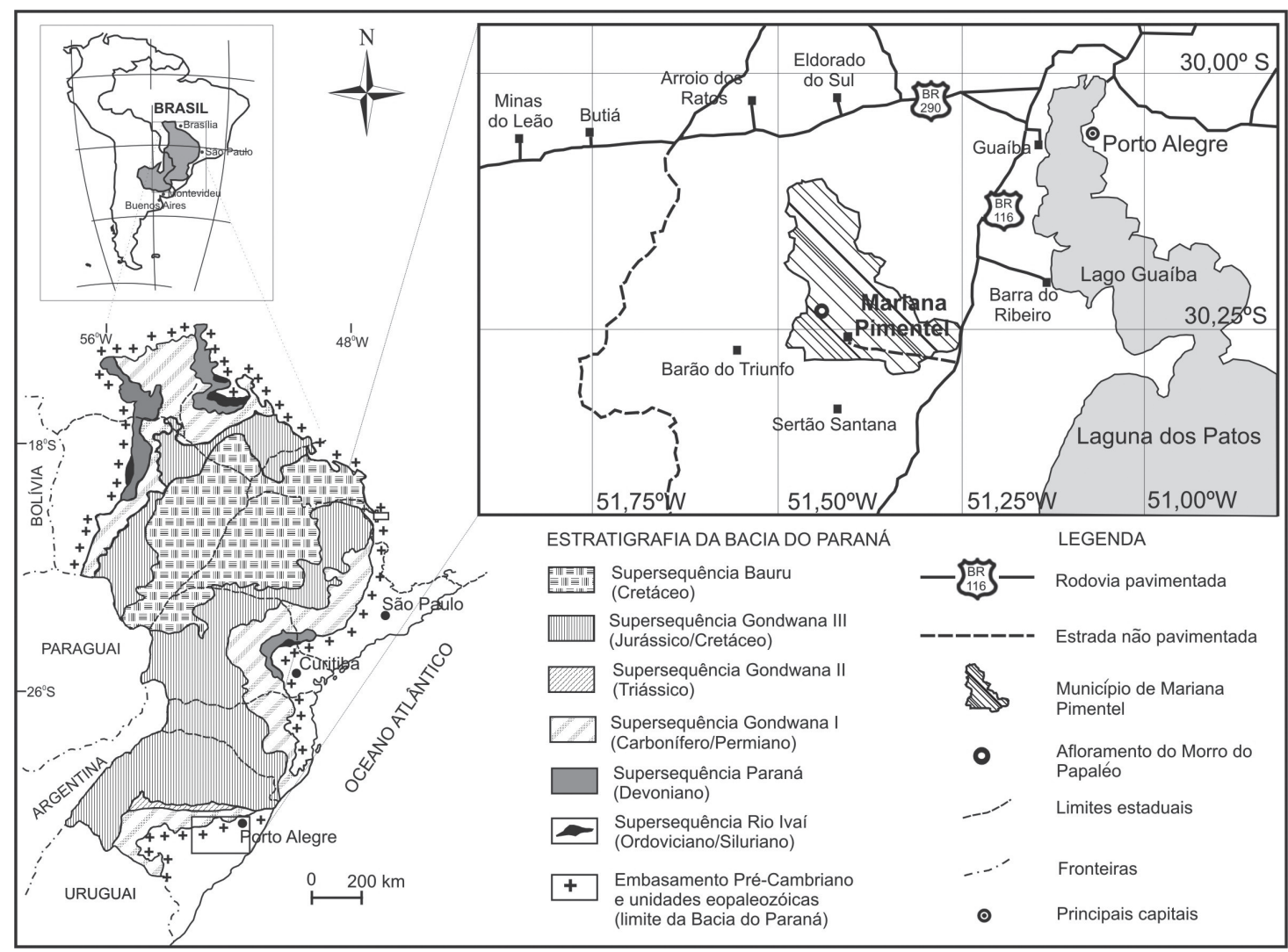

Figura 1. Distribuição das superseqüências estratigráficas da bacia do Paraná (a partir de Milani, 1997; modificado de Souza \& MarquesToigo, 2003) e localização do afloramento estudado.

Figure 1. Distribution of the Paraná Basin stratigraphic supersequences (after Milani, 1997; modified from Souza \& Marques-Toigo, 2003) and location map of the studied outcrop. 
finos centimétricos (Figura 2). As litofácies presentes no Morro do Papaléo representam o esquema de evolução paleogeográfica geral para o pacote eopermiano da bacia do Paraná no Rio Grande do Sul, postulado por vários autores (e.g., Lavina \& Lopes, 1987; Holz \& Carlucci, 2000). De modo geral, são representativas de ambiente marinho raso (Subgrupo Itararé) sucedidas por depósitos fluviais, deltaicos e de planície de inundação, com lagunas e baías costeiras formadoras de turfas (Formação Rio Bonito).

O conteúdo fossilífero da localidade é constituído por macrofósseis vegetais, icnofósseis e palinomorfos. Macrofósseis vegetais são, notadamente, os mais conhecidos (e.g., Corrêa da Silva, 1978; Cazzulo-Klepzig et al., 1980; Pasqualini et al., 1986; Guerra-Sommer \& Cazzulo-Klepzig, 1993; Vieira \& Iannuzzi, 2000; Iannuzzi et al., 2003), embora ainda haja carência de trabalhos de detalhe. A macroflora revela-se rica, sendo constituída por folhas, raízes, caules, sementes e estruturas reprodutivas de diversos grupos vegetais, tais como licófitas, pteridófitas, esfenófitas, filicófitas, cordaitaleanas, ginkgoaleanas e glossopteridales, cujos táxons foram relacionados e posicionados estratigraficamente no afloramento por Iannuzzi et al. (2003).

Em termos palinológicos, Burjack et al. (1982) registraram a presença de nove táxons em dois níveis de carvões da Formação Rio Bonito. No nível basal, são abundantes os gêneros Cyclogranisporites, Horriditriletes e Lundbladispora, enquanto que grãos de pólen são raros. Os gêneros Quadrisporites, Tetraporina e Pilasporites, relacionados ao grupo das algas, e Portalites, relacionado ao grupo de fungos (vide Souza, 2003, p. 55), são também comuns. No nível de carvão sobrejacente, os gêneros mais abundantes são Punctatisporites, Apiculatisporis, Cyclogranisporites, Horriditriletes e Lundbladispora.

Com base nos macrofósseis vegetais, o afloramento Morro do Papaléo foi posicionado no início do Permiano (Sakmariano/Artinskiano) e, por suas feições estratigráficas, foi considerado como uma localidade tipo da Formação Rio Bonito no Rio Grande do Sul (Corrêa da Silva, 1978; GuerraSommer \& Cazzulo-Klepzig, 1993). Em termos fitoestratigráficos, ali foram registrados táxons de macrofósseis vegetais que configuram o afloramento como estrato-tipo da Subzona Phyllotheca indica, do topo da Biozona Botrychiopsis plantiana de Guerra-Sommer \& Cazzulo-Klepzig (1993).

Além disso, Vieira \& Iannuzzi (2000) e Iannuzzi et al. (2003) assinalaram a presença de elementos da Subzona Gangamopteris obovata, base da Zona Botrychiopsis plantiana, na porção inferior do afloramento, e da Zona Glossopteris/Rhodeopteridium no topo, ampliando assim o registro fitoestratigráfico nesta seção.

\section{MATERIAIS E MÉTODOS}

Amostras de cinco diferentes níveis estratigráficos foram coletadas no afloramento Morro do Papaléo para processamento palinológico, dentre as quais, somente três revelaram resultados satisfatórios: uma correspondente ao

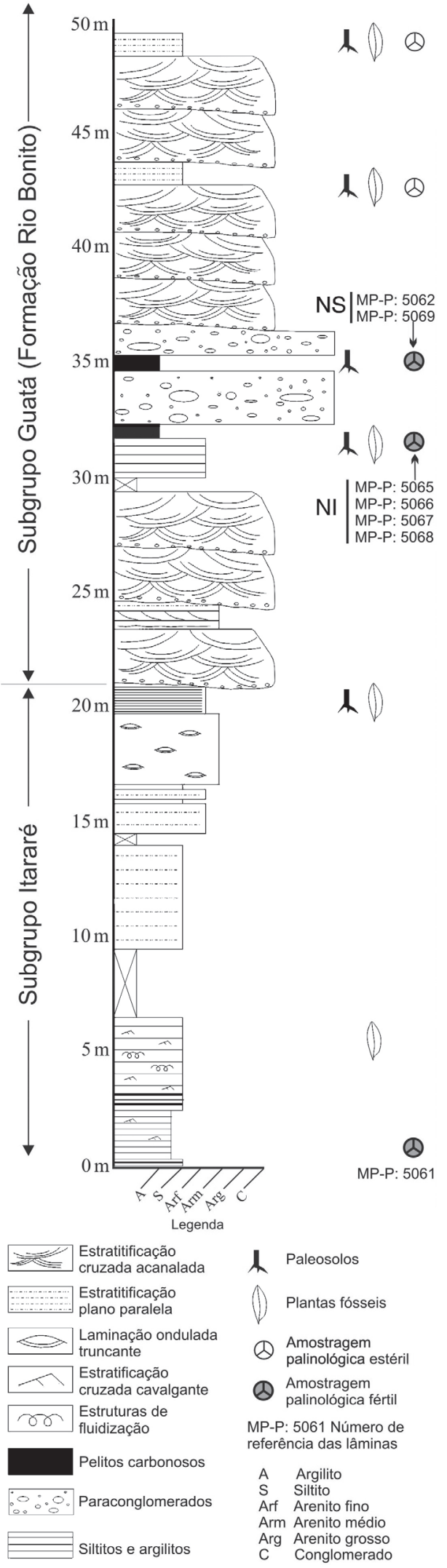

Figura 2. Seção estratigráfica do Morro do Papaléo (modificado de lannuzzi et al., 2003) com indicação dos níveis com macrofósseis vegetais e amostragem palinológica (NI, nível inferior; NS, nível superior). Figure 2. Stratigraphic section of the Morro do Papaléo (modified from lannuzzi et al., 2003) showing the levels with plant macrofossils and palynological sampling (NI, lower level; NS, upper level). 
siltito carbonoso do Subgrupo Itararé e duas aos pelitos carbonosos da Formação Rio Bonito (Figura 2).

As amostras foram processadas no Laboratório de Palinologia do Departamento de Paleontologia e Estratigrafia do Instituto de Geociências da UFRGS, conforme tratamento padrão para amostras paleozóicas, que consiste na desagregração física em almofariz e posterior dissolução dos constituintes minerais com ataque ácido ( $\mathrm{HCl}$ e HF). Os resíduos orgânicos foram concentrados por peneiração na fração entre 25 e $250 \mu \mathrm{m}$, resultando em lâminas palinológicas, depositadas na palinoteca do citado laboratório sob códigos MP-P 5061AD (Subgrupo Itararé); MP-P 5062A-E, 5065-5068, do nível inferior da Formação Rio Bonito; e, 5063A-C e 5069, do nível superior da referida unidade.

O material foi caracterizado quantitativamente e qualitativamente sob microscopia óptica em aumentos de 100 a 1.000 vezes, com contagem de, pelo menos, 200 espécimes por nível estratigráfico. A documentação fotomicrográfica foi realizada por captura de imagem em câmera digital Olympus acoplada ao microscópio Olympus BX51. A distribuição dos espécimes, por nível estratigráfico, é apresentada na Tabela 1. A análise quantitativa (Figura 3) baseou-se na presença de todos os elementos da matéria orgânica particulada, que incluem esporos, grãos de pólen, elementos relativos a algas, fungos e fitoclastos, reunindo um total de 12.079 constituintes, correspondentes a 9.167 elementos das lâminas do Subgrupo Itararé, 2.646 do nível inferior da Formação Rio Bonito e 266 do nível superior. A maioria dos espécimes é ilustrada nas Figuras 5 e 6 , devidamente codificados segundo sistema de quadrículas da lâmina England Finder (EF).

\section{RESULTADOS PALINOLÓGICOS}

As amostras revelaram palinofloras abundantes e diversificadas. A relação quantitativa dos elementos da matéria orgânica particulada registrada em cada nível amostrado é apresentada na Figura 3, considerando-se (Figuras 3A, D, G) ou não (Figuras 3B, E, H) os fitoclastos, cujos resultados são demonstrados em fotomicrografias selecionadas de cada nível (Figuras 3C, F, I). Dentre os esporomorfos, 20 espécies de esporos e 13 de grãos de pólen foram identificadas. Adicionalmente, são registradas cinco espécies microplanctônicas e uma espécie relativa a fungo, além de outras indeterminadas tentativamente atribuídas a fungos. A lista de espécies de palinomorfos mencionadas no texto encontra-se no Apêndice 1.

Esporos de gêneros afins às Sphenopsida (Calamospora, Reticulatisporites), Filicopsida (Punctatisporites, Cyclogranisporites, Granulatisporites, Horriditriletes, Convolutispora), Lycopsida (Lundbladispora, Cirratriradites, Kraeuselisporites, Vallatisporites, Cristatisporites) e Brevitriletes foram registrados, bem como gêneros de grãos de pólen afins às Gimnospermosida: Coniferales/Cordaitales (Cannanoropollis, Caheniasaccites, Divarisaccus, Limitisporites, Peppersites), Pteridospermales/ Glossopteridales (Vesicaspora, Protohaploxypinus, Illinites, Vittatina), Cycadales (Cycadopites) e Striomonosaccites, representam as paleocomunidades florísticas registradas nas palinofloras.

Na palinoflora do Subgrupo Itararé, dominam esporos cingulizonados, representados principalmente pelos gêneros Cristatisporites e Vallatisporites e, subordinadamente, por Kraeuselisporites e Lundbladispora. Por sua vez, os gêneros de esporos mais freqüentes nas palinofloras da Formação Rio Bonito são Lundbladispora e Punctatisporites e,

Tabela 1. Táxons identificados e distribuição na seção estudada. Table 1. Identified taxa and distribution in the studied section.

\begin{tabular}{|c|c|c|c|}
\hline Espécies & $\begin{array}{c}\text { Subgrupo } \\
\text { Itararé }\end{array}$ & $\begin{array}{c}\text { Formação } \\
\text { nível } \\
\text { inferior }\end{array}$ & $\begin{array}{l}\text { Rio Bonito } \\
\text { nível } \\
\text { superior }\end{array}$ \\
\hline \multicolumn{4}{|l|}{ Esporos } \\
\hline Brevitriletes levis & $x$ & $x$ & $x$ \\
\hline Calamospora hartungiana & $x$ & $x$ & $x$ \\
\hline Cirratriradites sp. & $x$ & & \\
\hline Convolutispora candiotensis & $x$ & $x$ & $x$ \\
\hline Cristatisporites irradiatus & $x$ & & \\
\hline Cristatisporites microvacuolatus & $x$ & & \\
\hline Cristatisporites morungavensis & $x$ & & \\
\hline Cyclogranisporites sp. & $x$ & & \\
\hline Granulatisporites triconvexus & $x$ & & \\
\hline Horriditriletes gondwanensis & $x$ & $x$ & $x$ \\
\hline Horriditriletes ramosus & $x$ & $x$ & $x$ \\
\hline Horriditriletes superbus & $x$ & $x$ & \\
\hline Horriditriletes uruguaiensis & $x$ & $x$ & \\
\hline Kraeuselisporites volkheimerii & $x$ & $x$ & $x$ \\
\hline Lundbladispora braziliensis & $x$ & $x$ & $x$ \\
\hline Lundbladispora riobonitensis & $x$ & $x$ & $x$ \\
\hline Punctatisporites gretensis & $x$ & $x$ & $x$ \\
\hline Reticulatisporites pseudopalliatus & $x$ & & \\
\hline Vallatisporites splendens & $x$ & & \\
\hline Vallatisporites ciliaris & $x$ & & \\
\hline \multicolumn{4}{|l|}{ GRÃOS DE PÓLEN } \\
\hline Cannanoropolis janakii & $x$ & $x$ & $x$ \\
\hline Cycadopites sp. & $x$ & & \\
\hline Divarisaccus stringoplicatus & $x$ & & \\
\hline Illinites unicus & $x$ & $x$ & $x$ \\
\hline Limitisporites sp. & $x$ & & \\
\hline Peppersites sp. & $x$ & & \\
\hline Protohaploxypinus goraiensis & $x$ & $x$ & $\mathrm{x}$ \\
\hline Protohaploxypinus limpidus & $x$ & $x$ & \\
\hline Striomonosaccites sp. & $x$ & & \\
\hline Vesicaspora sp. & $x$ & $x$ & $x$ \\
\hline Vittatina costabilis & $x$ & $x$ & $x$ \\
\hline Vittatina vittifera & $x$ & & \\
\hline \multicolumn{4}{|l|}{ ALGAS } \\
\hline Brazilea helby forma gregata & $x$ & & \\
\hline Brazilea scissa & $x$ & & \\
\hline Leiosphaeridia sp. & $x$ & & \\
\hline Tetraporina sp. & $x$ & $x$ & $x$ \\
\hline Quadrisporites horridus & $x$ & $x$ & \\
\hline \multicolumn{4}{|l|}{ FUNGOS } \\
\hline Portalites gondwanensis & $x$ & $x$ & $x$ \\
\hline Esporos de fungos indet. & $x$ & & \\
\hline
\end{tabular}


subordinadamente Horriditriletes. Grãos de pólen monossacados (Vesicaspora), bissacados teniados (Protohaploxypinus, Illinites) e poliplicados (Vittatina) são menos freqüentes nas amostras das duas unidades (Figura 3).

Algas representantes das Zignemataceae (Quadrisporites, Brazilea, Tetraporina) e Prasinoficeae (Leiosphaeridia) estão presentes em baixa quantidade, diferenciadamente nas palinofloras do Subgrupo Itararé e da Formação Rio Bonito. Dentre os fungos, Portalites gondwanensis está presente nas duas unidades, sendo mais abundante na Formação Rio Bonito (Figura 3).

Nas seções que se seguem, todos os táxons identificados são alfabeticamente listados, sendo sistematicamente apresentados e descritos aqueles selecionados dentre os inéditos para a bacia do Paraná (Horriditriletes gondwanensis e H. superbus) e com taxonomia aberta (Peppersites sp., Striomonosaccites sp., Leiosphaeridia sp.).

\section{DESCRIÇÕES}

Anteturma PROXIMEGERMINANTES Potonié 1970

Turma TRILETES Reinsch emend. Dettmann 1963

Suprasubturma ACAVATITRILETES Lüber emend. Dettmann 1963

Subturma AZONOTRILETES Dettmann 1963

Infraturma APICULATI Bennie \& Kidston emend. Potonié 1956

Subinfraturma BACULATI Dybová \& Jachowicz 1957

Gênero Horriditriletes Bharadwaj \& Salujha 1964

Horriditriletes gondwanensis (Tiwari \& Moiz) Foster 1975 (Figura 4E)

Lophotriletes rectus Kar \& Bose, 1967:21-22, est. 1, fig. 26. Lobatisporites gondwanensis Tiwari \& Moiz, 1971:98-99, est. 1, figs. 9-14, texto-fig. 2 .

\section{Formação Rio Bonito (nível superior)}

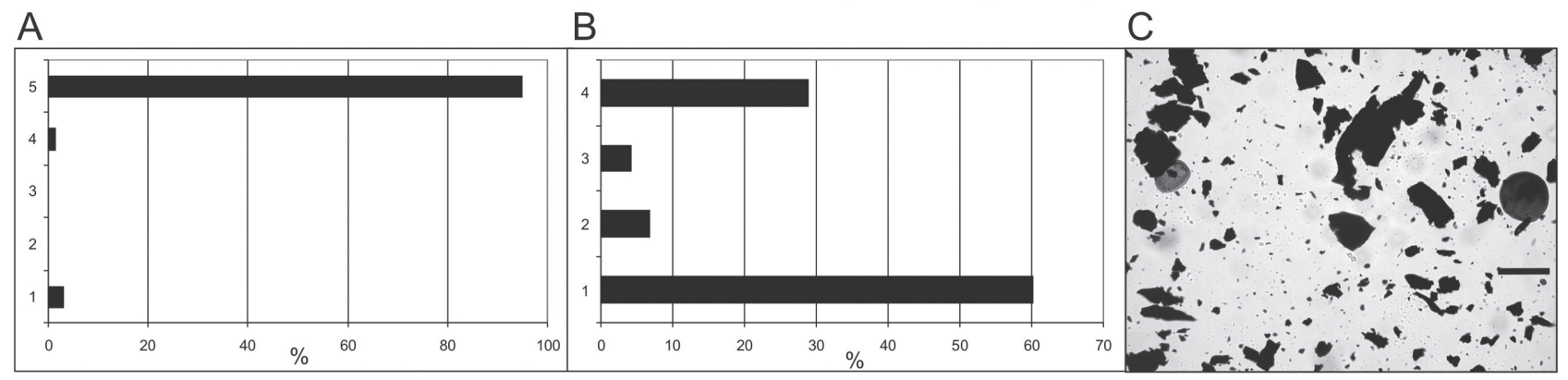

\section{Formação Rio Bonito (nível inferior)}
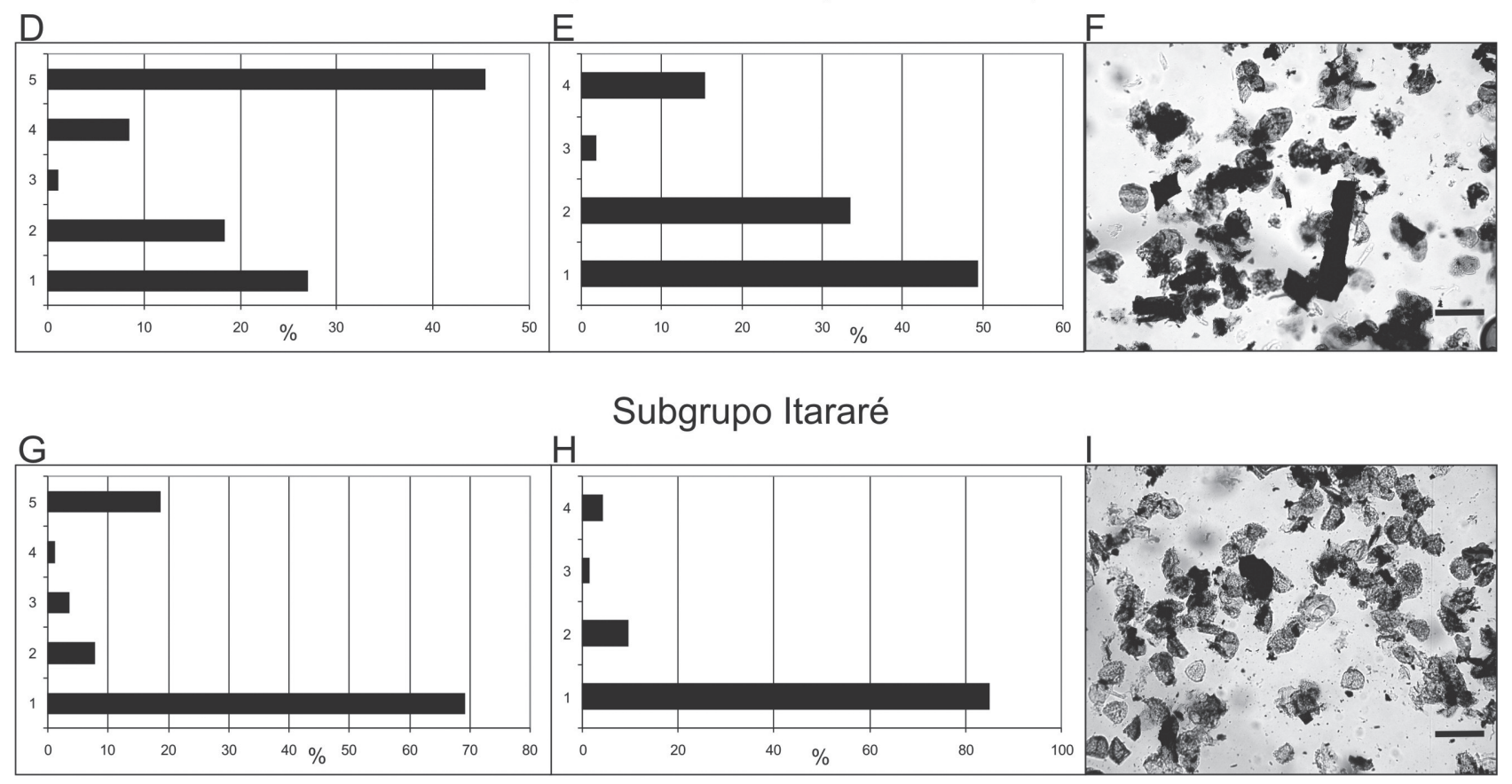

Figura 3. Freqüência relativa dos principais grupos da matéria orgânica particulada, considerando-se $(\mathbf{A}, \mathbf{D}, \mathbf{G})$ ou não (B, E, H) os fitoclastos e vista geral de lâminas selecionadas dos três níveis analisados $(\mathbf{C}, \mathbf{F}, \mathbf{I})$. Escala $=75 \mu \mathrm{m}(1$, esporos; 2 , grãos de pólen; 3 , fungos; 4, algas; 5, fitoclastos).

Figure 3. Quantitative distribution of the palynomorphs in the studied levels, with phytoclasts (A, D, G) or without them (B, E, H) and general view of selected slides $(\mathbf{C}, \mathbf{F}, \mathbf{I})$ to the three studied levels. Scale bar $=75 \mu \mathrm{m}$ (1, sporos; 2, pollen grains; 3, fungi; 4, algae; 5 , phytoclast). 

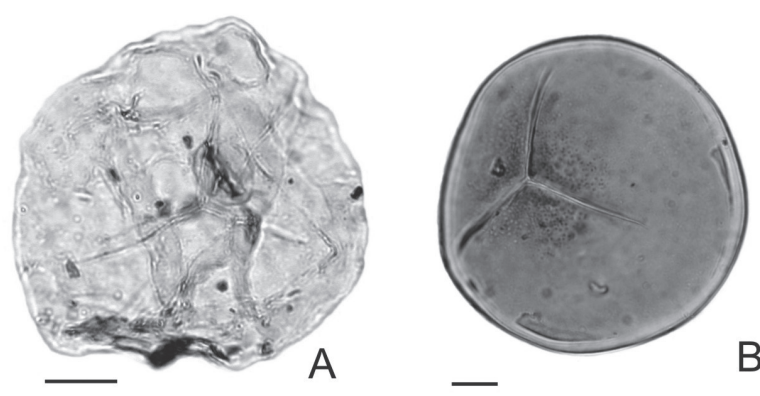

B
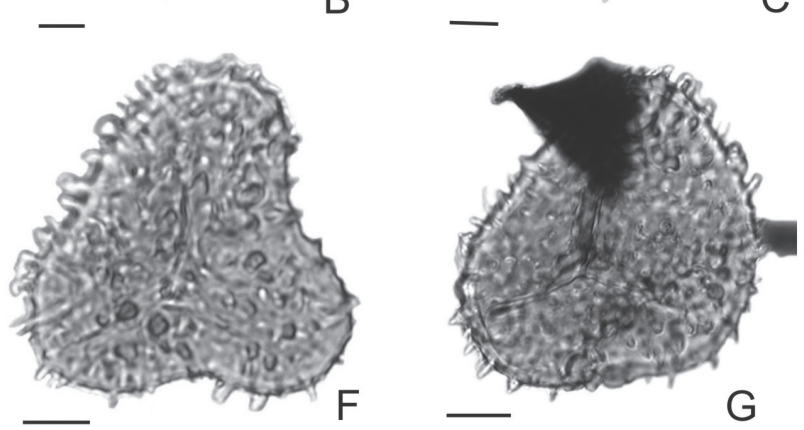

C
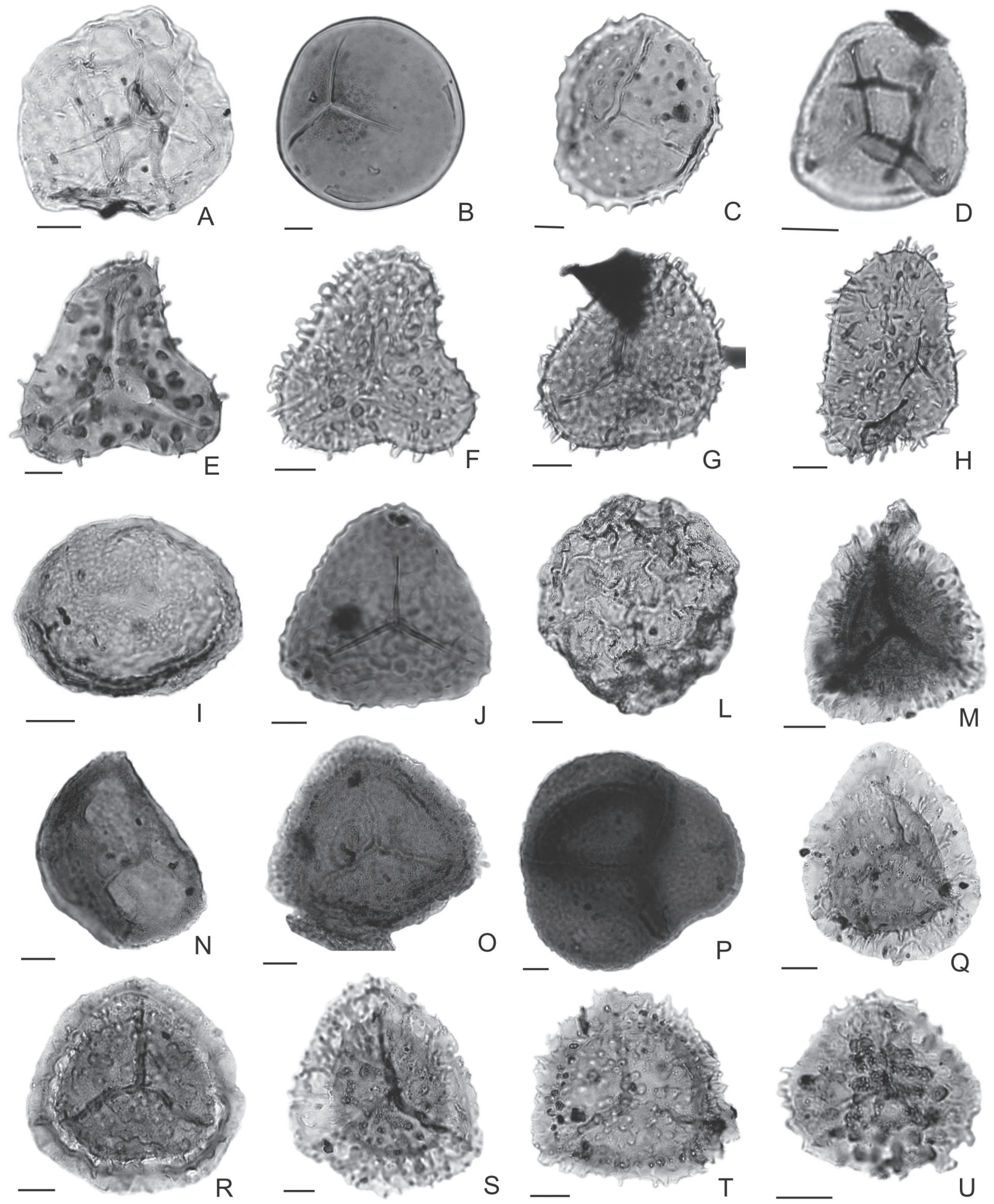

Figura 4. Táxons selecionados. Em parênteses, o número das lâminas e as coordenadas England Finder. A, Calamospora hartungiana (MP-P 5061A, S44-2); B, Punctatisporites gretensis (MP-P 5068, Y33-4); C, Brevitriletes levis (MP-P 5061B, R43-2); D, Granulatisporites triconvexus (MP-P 5061A, T52-3); E, Horriditriletes gondwanensis (MP-P 5062D, G35-4); F, Horriditriletes uruguaiensis (MP-P 5068, B46); G. Horriditriletes superbus (MP-P 5068, V36-3); H, Horriditriletes ramosus (MP-P 5068, U38-3); I, Cyclogranisporites sp. (MP-P 5061C, G44-2); J, Convolutispora candiotensis (MP-P 5065, A48-3); L, Reticulatisporites pseudopalliatus (MP-P 5061A, L59-3); M, Cirratriradites sp. (MP-P 5061B, M21); N, Lundbladispora riobonitensis (MP-P 5061B, V57-1); O, Lundbladispora braziliensis (MP-P 5061B, N56-2); P, Tétrade de Lundbladispora riobonitensis (MP-P 5065, M55-4); Q, Kraeuselisporites volkheimerii (MP-P 5061B, F53-4); R, Vallatisporites splendens (MP-P 5061B, L57-1); S, Vallatisporites ciliaris (MP-P 5061A, P41-4); T, Cristatisporites morungavensis (MP-P 5061C, E29); U, Cristatisporites microvacuolatus (MP-P 5061A, J40-2). Escala $=10 \mu \mathrm{m}$.

Figure 4. Selected taxa. In parenthesis, the slide number and England Finder coordinates. Scale bar $=10 \mu \mathrm{m}$. 

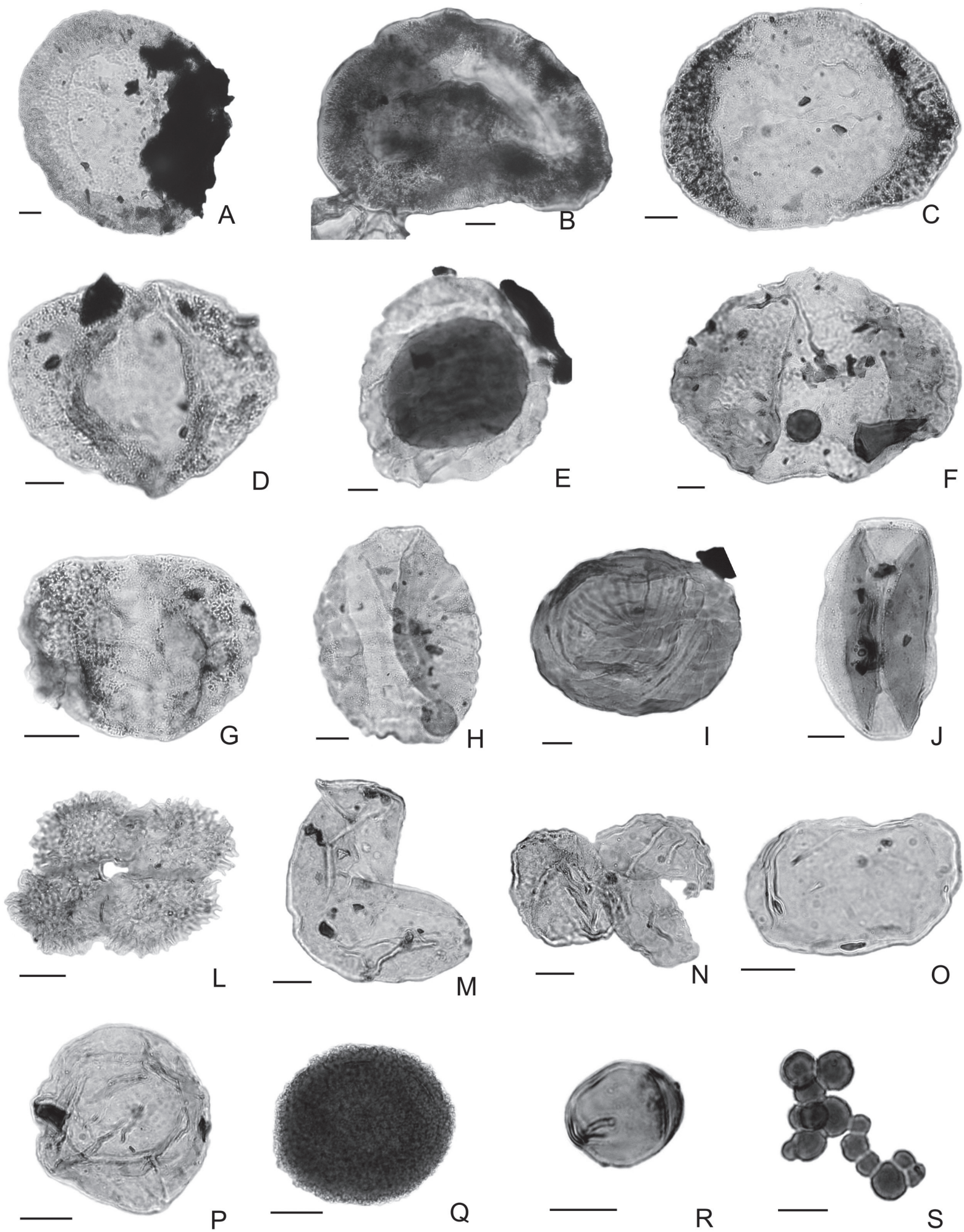

$\mathrm{R}$

Figura 5. Táxons selecionados. Em parênteses, o número das lâminas e as coordenadas England Finder. A, Cannanoropollis janakii (MPP 5061C, H29-2); B, Divarisaccus stringoplicatus (MP-P 5061B, P46-3); C, Peppersites sp. (MP-P 5061B, J43); D, Vesicaspora sp. (MP-P 5062D, G39-4); E, Striomonosaccites sp. (MP-P 5061B, J22-2); F, Limitisporites sp. (MP-P 5061B, K40-4); G, Protohaploxypinus limpidus (MP-5062C, R43-4); H, Vittatina costabilis (MP-P 5061B, N51-4); I, Vittatina vittifera (MP-P 5061B, Q52-1); J, Cycadopites sp. (MP-P 5061A, O47-1); L, Quadrisporites horridus (MP-P 5069, E56-1); M, Brazilea scissa (MP-P 5061A, H47-1); N. Brazilea helby forma gregata (MP-P 5061A, F49-4); O, Tetraporina sp. (MP-P 5061A, G47-2); P, Leiosphaeridia sp. (MP-P 5061C, F35-3); Q, Portalites gondwanensis (MP-P 5061C, R34); R-S, Esporos de fungos indeterminados (R, MP-P 5061A, K50; S, MP-P 5061A, P54-2). Escala = $10 \mu \mathrm{m}$.

Figure 5. Selected taxa. In parenthesis, the slide number and England Finder coordinates. Scale bar $=10 \mu \mathrm{m}$. 
Horriditriletes gondwanensis (Tiwari \& Moiz) Foster, 1975: 132, est. 2, figs. 5-7.

Descrição. Esporo trilete de contorno equatorial triangular, com lados marcadamente côncavos e ápices arredondados. Exina ornamentada em ambas as faces por espinhos, báculas e cones em proporções variadas ( 1 a $3 \mu \mathrm{m}$ de base, 2 a $5 \mu \mathrm{m}$ de altura). Na face proximal, a ornamentação é mais espaçada.

Dimensões. Diâmetro equatorial 28 e $37 \mu \mathrm{m}$ (2 espécimes).

Comparação. H. uruguaiensis apresenta ornamentação mais reduzida e lados menos côncavos.

Distribuição estratigráfica. Permiano da Índia (Tiwari \& Moiz, 1971), Austrália (Foster, 1975) e Zaire (Kar \& Bose, 1967).

Observações. Os raios da marca trilete são de difícil observação devido à densa ornamentação. Espécie inédita para a bacia do Paraná.

\section{Horriditriletes superbus (Foster) Césari, Archangelsky \& Seoane 1995}

(Figura 4G)

Acanthotriletes superbus Foster, 1979:34-35, est. 5, figs. 20-25. Horriditriletes superbus (Foster) Césari et al., 1995:77, est. 1, fig. 7.

Descrição. Esporo radial, trilete triangular de lados convexos a retos e ápices arredondados. Raios da marca trilete retos a sinuosos, atingindo $3 / 4$ do raio do esporo. Exina ornamentada em ambas as faces, predominando espinhos ( 1 a $2 \mu \mathrm{m}$ de base, 4 a 5 $\mu \mathrm{m}$ de altura), com verrugas, cones e elementos mameliformes subordinados ( 1 a $2 \mu \mathrm{m}$ de base, 1 a $3 \mu \mathrm{m}$ de altura).

Dimensões. Diâmetro equatorial $50 \mu \mathrm{m}$ (1 espécime).

Comparação. Distingue-se das demais espécies do gênero pela predominância de espinhos como elementos ornamentais. Distribuição estratigráfica. Carbonífero Superior? a Permiano da Argentina (Césari et al., 1995); Permiano da Austrália (Foster, 1979).

Observações. Espécie inédita para a bacia do Paraná.

\author{
Anteturma VARIEGERMINANTES Potonié 1970 \\ Turma SACCITES Erdtmann 1947 \\ Subturma MONOSACCITES Chitaley emend. \\ Potonié \& Kremp 1954 \\ Infraturma MONOPOLSACCITI Hart emend. Dibner 1971 \\ Gênero Peppersites Ravn 1979 \\ Peppersites sp. \\ (Figura 5C)
}

Descrição. Grão de pólen monossacado, de simetria bilateral, alongado longitudinalmente, contorno ovalado. Corpo central indistinto, acompanhando a forma geral do grão; marca monolete incipiente. Saco intramicroreticulado, relativamente pequeno em comparação ao corpo central.

Dimensões. Eixo longitudinal total $82 \mu \mathrm{m}$, eixo transversal total $59 \mu \mathrm{m}$, eixo longitudinal do corpo central $51 \mu \mathrm{m}$, eixo transversal do corpo central $53 \mu \mathrm{m}$ (1 espécime).

Observações. A relação entre as dimensões do corpo central e do saco sugere o posicionamento no gênero. No entanto, melhor determinação específica é dificultada pela pouca definição do corpo central, o qual, na espécie tipo (Peppersites ellipticus Ravn 1979), é notadamente denso e mais espesso.

Infraturma STRIASACCITI Bharadwaj 1962

Gênero Striomonosaccites (Bharadwaj) Hart 1965

Striomonosaccites sp.

(Figura 5E)

Striomonossacites sp., Daemon \& Quadros, 1970:384-385, est. 7, pars. (forma P-385).

Striomonosaccites sp., Menéndez, 1971:294, est. VI, fig. 4.

Striomonosaccites sp., Gutiérrez \& Césari, 2000:454.

Descrição. Grão de pólen monossacado, com contorno equatorial ovalado a subcircular. Corpo central bem marcado, espesso, de contorno circular a subcircular. Exina intramicroreticulada, livre do saco também na face distal, com sete tênias paralelas na face proximal, com largura irregular (2$4 \mu \mathrm{m})$, de aspecto grano-verrucoso. Saco intramicroreticulado. Dimensões. Diâmetro equatorial total 52-59 $\mu \mathrm{m}$, diâmetro equatorial do corpo central 33-40 $\mu \mathrm{m}$ (1 espécime).

Comparações. Oespécime descrito confere com Striomonosaccites sp. (P-385) de Daemon \& Quadros (1970), relativo a formas com número de tênias (6 a 20) e diâmetro equatorial total (38-117 $\mu \mathrm{m}$ ) variáveis, ocorrentes desde o Subgrupo Itararé até a Formação Palermo (intervalos I a K). Striomonosaccites sp. descrito por Menéndez (1971) e registrado por Gutiérrez \& Césari (2000) é muito semelhante, embora somente na ilustração do primeiro autor seja possível inferir o caráter irregular das tênias. Striomonosaccites sp. descrito por Menéndez (1976) é muito semelhante, mas apresenta tênias orientadas concordantemente ao eixo de maior alongamento. Striomonosaccites cicatricosus Archangelsky \& Gamerro 1979 possui maior número de tênias (14-30) e dimensão total (64-120 $\mu \mathrm{m})$.

Observações. Para Daemon \& Quadros (1970), as variações nas dimensões e número de tênias observadas em Striomonosaccites sp. (P-385) refletiriam a presença de distintos táxons no mesmo intervalo estratigráfico. Provavelmente, somente o número de tênias (6 a 20 tênias) parece ser distintivo entre uma parte dos espécimes de Daemon \& Quadros (1970) e S. cicatricosus (14 a 30 tênias). Césari et al. (1995) descreveram um espécime atribuído a este último táxon, com dimensões ligeiramente menores $(60 \mu \mathrm{m})$ do que consta em sua diagnose, e próximas ao espécime aqui descrito.

Divisão PRASINOPHYTA Round 1971
Ordem PYRAMIMONADALES Schiller 1925
Família LEIOSPHAERIDACEAE Sommer emend.
Sommer \& Van Boekel 1963
Gênero Leiosphaeridia Eisenack 1958
Leiosphaeridia sp.
(Figura 5P)

Descrição. Vesícula de contorno circular. Parede lisa, fina $(<$ $0,5 \mu \mathrm{m}$ ) e intensamente dobrada de forma irregular, com presença de estrutura de encistamento. 
Dimensões. Diâmetro total 43 e 46 m (2 espécimes). Comparações. Os espécimes observados se assemelham a $L$. tenuissima Eisenack 1958. No entanto, o número de espécimes e a forte compressão da exina, que promove intenso dobramento na vesícula, impedem melhor determinação taxonômica. Espécimes semelhantes foram registrados para o Permiano do Gondwana: Leiosphaeridia sp. A, descrita para o Permiano na Austrália (Backhouse, 1991), Leiosphaeridia sp. A, descrita para o Permiano da Antártida (Lindström, 1995) e Leiosphaeridia sp., descrita para o Permiano do Uruguai (Beri et al., 2006).

\section{DISCUSSÃO}

\section{Bioestratigrafia e idade}

O esquema bioestratigráfico mais atualizado para o Paleozóico Superior da bacia do Paraná é o apresentado por Souza \& Marques-Toigo (2003, 2005), que incluíram e redefiniram as zonas anteriormente propostas por Daemon \& Quadros (1970), Marques-Toigo (1988, 1991) e os resultados de Souza (2000), estes últimos posteriormente publicados em Souza (2006). De acordo com esses trabalhos, quatro zonas de intervalo foram identificadas para a bacia do Paraná: Ahrensisporites cristatus, Crucisaccites monoletus, Vittatina costabilis e Lueckisporites virkkiae, em ordem estratigráfica ascendente. Destas, somente duas foram reconhecidas no Estado do Rio Grande do Sul: Zona Vittatina costabilis e Zona Lueckisporites virkkiae. A primeira, subdividida nas subzonas Protohaploxypinus goraiensis e Hamiapollenites karroensis, foi registrada a partir de estratos relativos ao Subgrupo Itararé até o topo da Formação Rio Bonito. A partir do topo desta última unidade, ocorre a Zona Lueckisporites virkkiae, que se estende até estratos da Formação Teresina (Souza \& Marques-Toigo, 2005).

Em ambas as unidades estratigráficas aflorantes no Morro do Papaléo, Subgrupo Itararé e Formação Rio Bonito, foram registradas espécies diagnósticas da Zona Vittatina costabilis, a saber: Vittatina costabilis, Protohaploxypinus goraiensis, P. limpidus e Illinites unicus, que permitem o posicionamento bioestratigráfico na Subzona Protohaploxypinus goraiensis. A ausência de espécies índices das zonas palinológicas de idade carbonífera ocorrentes na porção inferior (Zona Ahrensisporites cristatus) e média (Zona Crucisaccites monoletus) do Subgrupo Itararé (Souza, 2006), bem como de formas típicas da Zona Lueckisporites virkkiae, restringem seu posicionamento na Zona Vittatina costabilis. Formas guias, tais como Hamiapollenites karroensis e Striatopodocarpites fusus, que ocorrem a partir da Subzona Hamiapollenites karroensis, são ausentes, descartando assim a inclusão das palinofloras analisadas nesta subzona.

As associações palinológicas registradas aqui são típicas da transição entre o Subgrupo Itararé e a Formação Rio Bonito, ao longo de toda a bacia do Paraná, reunindo espécies guias de uma única subzona (e.g., P. goraiensis) e elementos comuns, principalmente esporos cingulizonados e grãos de pólen monossacados. Conjuntos correlatos são conhecidos desde a porção setentrional da bacia (e.g., Souza \& Callegari, 2004) até sua porção mais meridional em território brasileiro (e.g., Ybert, 1975; Dias-Fabrício, 1981; Dias, 1993) e uruguaio (e.g., Beri \& Daners, 1998; Beri et al., 2006).

Em termos de macrofósseis vegetais, correlações com o zoneamento paleoflorístico proposto por Guerra-Sommer \& Cazzulo-Klepzig (1993) são dificultadas pela ausência de um significativo registro macrofitofossilífero nos níveis de onde foram extraídas as palinofloras analisadas. A megaflora registrada no Subgrupo Itararé, coletada em nível situado poucos metros acima (Nível 2 de Iannuzzi et al., 2003) daquele no qual a palinoflora foi obtida, compõe-se de apenas uns poucos elementos longevos, a saber: Botrychiopsis plantiana, Gangamopteris angustifolia, G. obovata, Glossopteris communis, Cordaites hislopii, Samaropsis sp. e Cordaicarpus sp. Dentre estes elementos, destaca-se a presença de Botrychiopsis plantiana, Gangamopteris angustifolia e G. obovata, espécies guias que possibilitam o posicionamento bioestratigráfico na Subzona Gangamopteris obovata da Zona Botrychiopsis plantiana (conforme GuerraSommer \& Cazzulo-Klepzig, 1993). Desta forma, sugere-se que a palinoflora proveniente do Subgrupo Itararé corresponda a esta subzona.

Em relação às palinofloras obtidas nos estratos mais superiores da Formação Rio Bonito, o registro paleoflorístico associado é bastante escasso, porém de significado bioestratigráfico. Nos pelitos carbonosos de onde se extraíram os palinomorfos foram coletados restos caulinares de licófita, cf. Brasilodendron sp., e de uma provável glossopterídea, ?Vertebraria sp. Tendo em vista que as licófitas estão restritas à Zona Glossopteris/Rhodeopteridium (Guerra-Sommer \& Cazzulo-Klepzig, 1993; Iannuzzi et al., 2003), sugere-se uma correspondência entre as palinofloras da Formação Rio Bonito aqui analisadas com esta fitozona.

A idade apontada por Souza \& Marques-Toigo (2005) para a Subzona Protohaploxypinus goraiensis é relativa ao Eopermiano, provavelmente base do Cisuraliano (Asseliano/ Sakmariano), corroborada pela datação absoluta (U/Pb SHRIMP zircão) apresentada por Santos et al. (2006). Estes autores obtiveram uma idade artinskiana $(278,4 \pm 2,2 \mathrm{Ma})$ para a Formação Irati no Estado do Paraná. Considerando que esta unidade é relativamente isócrona ao longo da bacia e constitui datum estratigráfico (Daemon \& Quadros, 1970), as idades para as unidades subjacentes do Grupo Tubarão seriam necessariamente Artinskiana inicial (topo da Formação Rio Bonito e formação Palermo) e pré-Artinskiana (Subgrupo Itararé e porções inferior e média da Formação Rio Bonito). Por outro lado, porções inferior e média do Subgrupo Itararé equivalentes às zonas Ahrensisporites cristatus e Crucisaccites monoletus, respectivamente, foram considerados por Souza (2006) como pensilvanianos (Carbonífero Superior). No Rio Grande do Sul, depositaram-se apenas os níveis correspondentes à porção superior do Subgrupo Itararé, considerados como eopermianos (Asseliano/Sakmariano). Dessa forma, os níveis do Morro do Papaléo (topo do Subgrupo Itararé e porção inferior/média da Formação Rio Bonito) estariam posicionados no Eopermiano (Asseliano/Sakmariano). 


\section{Aspectos paleoambientais}

A análise da frequiência dos elementos constituintes da matéria orgânica particulada do Subgrupo Itararé, com o domínio de esporos cingulizonados (e.g., Cristatisporites, Vallatisporites) representando a vegetação pteridofítica, indica proximidade continental. A presença de tétrades de esporos e o baixo grau de arredondamento dos fitoclastos sugerem pouca ação de transporte entre a área fonte e o sítio de deposição. Algas relativas às Zignemataceae (e.g., Quadrisporites, Tetraporina) foram registradas nas duas unidades. A presença destes elementos no Subgrupo Itararé evidencia o aporte continental, a partir de drenagens em sistemas fluviais/deltaicos. Por outro lado, a presença de algas do tipo Leiosphaeridia sp. indica influência marinha no depósito. Esta última interpretação corrobora informações litofaciológicas prévias para a unidade no Estado (Holz \& Carlucci, 2000; Silveira, 2000). Leiosphaeridia sp. foi registrada em sedimentos periglaciais na Antártida (Lindström, 1995) e na Austrália (Backhouse, 1991), posicionados em zonas bioestratigráficas correlatas à Zona Vittatina costabilis da bacia do Paraná. Na Antártida (Lindström, 1995) e na bacia do Paraná (Dias, 1993), sua presença foi interpretada como indicativa de ambiente marinho. $\mathrm{O}$ gênero tem sido comumente descrito em depósitos de origem marinha de diversas idades. (e.g. Downie, 1973; Ottone, 1996).

Interpretações a partir do conteúdo paleoflorístico são dificultadas pela ausência de registro macrofitofossilífero exatamente nos níveis de onde provêm as palinofloras analisadas. A megaflora registrada no Subgrupo Itararé, poucos metros acima da associação palinológica (Nível 2 de Iannuzzi et al., 2003), indica uma maior proximidade da linha de costa, destacando-se a presença de Botrychiopsis plantiana que tem sido, por um lado, uma forma indicadora de condições climáticas mais frias (Retallack, 1980; GuerraSommer, 1989) e, por outro, da ocorrência de ambientes transicionais, onde abundam juntamente com folhas do tipo Gangamopteris sp. em associações gondvânicas correlatas (Retallack, 1980). Ambas as afirmações coadunam-se às interpretações feitas a partir dos palinomorfos e litofácies citadas acima.

A configuração de corpos lagunares e pantanosos da Formação Rio Bonito, nos quais se desenvolveram os pelitos carbonosos, é constatada a partir da litofaciologia e do registro de Zignemataceae, além de espécies de fungos (e.g., Portalites), relativamente mais abundantes nesta unidade que no Subgrupo Itararé, típicos de corpos de água calmos, com relativa estagnação. Fitoclastos opacos são os elementos dominantes nos dois níveis da Formação Rio Bonito, com destaque ao nível superior, onde atinge aproximadamente 95\% (Figura 3), apresentando-se angulosos e mal selecionados. Essas informações corroboram a interpretação de um processo sedimentar de baixa energia no sítio deposicional, como exemplificado por Batten \& Stead (2005) na caracterização das palinofácies de ambiente lacustre (tipo XII) e pantanoso (XV).

As licófitas, provavelmente do tipo Brasilodendron, encontradas em associação com os palinomorfos da
Formação Rio Bonito, são plantas normalmente associadas a ambientes parálicos ou pantanosos, sendo consideradas como um dos principais elementos formadores dos depósitos carbonosos do Estado (Guerra-Sommer, 1989). Deste modo, sua presença corrobora as interpretações obtidas a partir dos palinomorfos e delineadas acima.

\section{CONCLUSÕES}

Os conjuntos palinológicos registrados nos níveis do Subgrupo Itararé e da Formação Rio Bonito permitem o posicionamento destas unidades, aflorantes no Morro do Papaléo, na Subzona Protohaploxypinus goraiensis, base da Zona Vittatina costabilis, de idade eopermiana (Asseliano/ Sakmariano), pela presença de espécies guias comuns. Não há diferenciação bioestratigráfica entre os níveis estudados das duas unidades, o que corrobora resultados bioestratigráficos prévios (Daemon \& Quadros, 1970) para a transição entre o topo do Subgrupo Itararé e a base da Formação Rio Bonito ao longo da bacia. Por outro lado, demonstra-se que a Subzona $P$. goraiensis corresponde a duas fitozonas distintas, ou seja, as zonas Botrychiopsis plantiana e Glossopteris/Rhodeopteridium de Guerra-Sommer \& Cazzulo-Klepzig (1993). Este fato tem sido interpretado como indicativo de que as referidas fitozonas possam, na realidade, representar "ecozonas" controladas faciologicamente e não unidades bioestratigráficas operacionais, conforme foi sugerido anteriormente por Iannuzzi et al. (2003).

Do ponto de vista paleoecológico, há diferenças significativas, notadamente expressadas pelas porcentagens dos grupos da matéria orgânica particulada, com a maior participação de esporos no Subgrupo Itararé e fitoclastos na Formação Rio Bonito. O registro de Leiosphaeridia sp. na primeira unidade confere influência marinha, que pode ser entendida como marinho raso a transicional (lagunar/frente deltaica). Por outro lado, a presença de formas de algas atribuídas às Zignemataceae e fungos, bem como a natureza e os caracteres morfológicos dos fitoclastos, corroboram o paleoambiente continental de baixa energia (lacustre/pantanoso) para a Formação Rio Bonito, relacionado à gênese dos pelitos carbonosos.

\section{AGRADECIMENTOS}

Os dois primeiros autores agradecem, respectivamente, à PROPESQ/UFRGS e ao PIBIC/CNPq/UFRGS pela concessão de bolsa de iniciação científica. Este trabalho foi realizado com recursos de projetos vinculados à FAPERGS (02/1755-2, 04/1066-0) e ao CNPq (PQ 303368/2004-0, PQ 304655/2004-0, APQ 474153/2004-5) e constitui uma contribuição do Centro de Investigações do Gondwana (CIGO) ao Projeto IGCP 471. Os autores dedicam este trabalho a Marleni Marques-Toigo (in memoriam), pela sua participação nos estudos iniciais do material e pela sua contribuição na geração de conhecimentos e formação de recursos humanos no Laboratório de Palinologia do IG/UFRGS. Este trabalho foi uma contribuição ao XIX Congresso Brasileiro de Paleontologia/VI Congresso Latinoamericano de Paleontologia, ocorrido em Aracajú, SE, em agosto de 2005. 


\section{REFERÊNCIAS}

Archangelsky, S. \& Gamerro, J.C. 1979. Palinologia del Paleozóico Superior em el subsuelo de la Cuenca Chacoparanense, República Argentina. I. Estudio sistemático de los palinomorfos de tres perfaciones de la Província de Córdoba. Revista Española de Micropaleontologia, 11(3):417-478.

Backhouse, J. 1991. Permian palynostratigraphy of the Colie Basin, Western Australia. Review of Paleobotany and Palynology, 67:237-314.

Batten, D.J. \& Stead, D.T. 2005. Palynofacies analysis and its stratigraphic application. In: E.A.M. Koutsoukos (ed.) Applied Stratigraphy. Dordrecht, Springer, p. 203-226.

Beri, A. \& Daners, G. 1998. Estudio palinológico de la perforación 201 (DI.NA.MI.GE), Pérmico, Uruguay. Boletín de la Real Sociedad Española de Historia Natural (Sec. Geol.), 94(1/2):55-64.

Beri, A.; Gutiérrez, P.R.,; Cernuschi, F. \& Balarino, M.L. 2006. Palinología del Pérmico Inferior en la perforación DCLS-24 (Formación San Gregorio), departamento de Cerro Largo, Uruguay. Parte I: esporas, algas, prasinofitas y acritarcas. Ameghiniana, 43(1):227.244.

Burjack, M.I.A.; Cazzulo-Klepzig, M.; Dias-Fabrício, M.A.; Guerra-Sommer, M.; Marques-Toigo, M.; Paim, P.S. \& Lavina, E.L. 1982. Perfil paleoecológico do afloramento Morro do Papaléo, Permiano Inferior da bacia do Paraná, Rio Grande do Sul, Brasil. In: CONGRESSO BRASILEIRO DE GEOLOGIA, 32, 1982. Anais, Salvador, SBG, 4:1260-1270.

Cazzulo-Klepzig, M.; Guerra-Sommer, M. \& Bossi, G.E. 1980. Revisão fitoestratigráfica do Grupo Itararé no RS. I Acampamento Velho, Cambaí Grande, Budó e Morro do Papaléo. Boletim IG-USP, 11:55-76.

Césari, S.; Archangelsky, S. \& Seoane, L.V. 1995. Palinologia del Paleozóico Superior de la perforación las Mochas, província de Santa Fé, Argentina. Ameghiniana, 32(1):73-106.

Corrêa da Silva, Z.C. 1978. Observações sobre o Grupo Tubarão no Rio Grande do Sul com especial destaque à estratigrafia da Formação Itararé. Pesquisas, 9:9-61.

Corrêa da Silva, Z.C. \& Arrondo, O.G. 1977. Tafoflora permiana de Mariana Pimentel, município de Guaíba, Rio Grande do Sul, Brasil. Pesquisas, 7:27-44.

Daemon, R.F. \& Quadros, L.P. 1970. Bioestratigrafia do Neopaleozóico da bacia do Paraná. In: CONGRESSO BRASILEIRO DE GEOLOGIA, 24, 1970. Anais, Brasília, SBG, p. 359-412.

Dias, M.E.R. 1993. Associações microflorísticas dos paleovales do Grupo Itararé no Rio Grande do Sul, Permiano da bacia do Paraná, Brasil. Pesquisas, 20(2):132-140.

Dias-Fabrício, M.E. 1981. Palinologia da Formação Rio Bonito na área de Gravataí-Morungava, Rio Grande do Sul. Pesquisas, 14:69-130.

Downie, C. 1973. Observations on the nature of the acritharchs. Paleontology, 16(2):239-259.

Foster, C.B. 1975. Permian plant microfossils from the Blair Athol Coal Measures, Central Queensland, Austrália. Palaeontographica, Abt B 154(5-6):121-171.

Foster, C.B. 1979. Permian plant microfossils of the Blair Athol Coal Measures, Baralaba Coal Measures, and Basal Rewan Formation of Queensland. Geological Survey of Queensland, 372(45):1-154.

Guerra-Sommer, M. 1989. Megafloras ocorrentes em horizontes associados a carvões no Rio Grande do Sul. Acta Geologica Leopoldensia, 29(12):93-122.

Guerra-Sommer, M. \& Cazzulo-Klepzig, M. 1993. Biostratigraphy of the Southern Brazilian Neopaleozoic Gondwana Sequence: a preliminary paleobotanical approach. In: INTERNATIONAL CONGRÈS DE LA STRATIGRAPHIE ET GÉOLOGIE DU CARBONIFÈRE ET PERMIEN, 12, 1991. Comptes Rendus, Buenos Aires, 2:61-72.

Gutiérrez, P.R. \& Césari, S.N. 2000. Palinología de la Formación Bajo de Vélez (Pérmico Inferior), San Luis, Argentina: revisión sistemática y consideraciones bioestratigráficas. Ameghiniana, 37(4):439-462.

Holz, M. \& Carlucci, R. 2000. Litoestratigrafia, estratigrafia de sequiências e evolução paleofisiográfica da zona de borda da Bacia do Paraná no Rio Grande do Sul durante o Eo-permiano. In: M. Holz \& L.F. De Ros (eds.) Geologia do Rio Grande do Sul, CIGO/UFRGS, p. 303-322.

Iannuzzi, R.; Marques-Toigo, M.; Scherer, C.M.S.; Caravaca, G.; Vieira, C.E.L. \& Pereira, L.S. 2003. Reavaliação da fitobioestratigrafia da seqüência gonduânica sul-riograndense: estudo de caso do afloramento Morro do Papaléo (Bacia do Paraná, Permiano Inferior). In: ENCONTRO SOBRE A ESTRATIGRAFIA DO RIO GRANDE DO SUL: ESCUDO E BACIAS, 2003. Anais, Porto Alegre, p. 183-185.

Kar, R.K. \& Bose, M.N. 1967. Paleozoic sporae dispersae from Congo III. Assisses des schistes noirs de la Lukuga. Annales $d u$ Musee Royal de L'Afrique Centrale Serie IN-8 ${ }^{\circ}$, 54:1-59.

Lavina, E. L. \& Lopes, R.C. 1987. A transgressão marinha do Permiano Inferior e a evolução paleogeográfica do Supergrupo Tubarão no Estado do Rio Grande do Sul. Paula-Coutiana, 1:51-103.

Lindström, S. 1995. Early Permian palinostratigraphy of the northern Heimefrontfjella Mountain-Range, Dronning Maud Land, Antarctica. Review of Paleobotany and Palynology, 89:359-415.

Marques-Toigo, M. 1988. Palinologia, bioestratigrafia e paleoecologia do Neopaleozóico da Bacia do Paraná nos estados do Rio Grande do Sul e Santa Catarina, Brasil. Programa de Pós-graduação em Geociências, Universidade Federal do Rio Grande do Sul, Tese de Doutoramento, 259 p.

Marques-Toigo, M. 1991. Palynobioestratigraphy of the Southern Brazilian Neopaleozoic Gondwana sequence. In: INTERNACIONAL GONDWANA SYMPOSIUM, 7, 1988. Proceedings, São Paulo, p. 503-515.

Menéndez, C.A. 1971. Estudio palinológico del Pérmico de Bajo de Valez, Província de San Luis. Revista del Museo Argentino de Ciencias Naturales “Bernardino Rivadavia”, Paleontología, 1(9):263-306.

Menéndez, C.A. 1976. Contenido palinológico de estratos pérmicos com "Mesosaurus" de Rio Claro, São Paulo, Brasil. Revista del Museo Argentino de Ciencias Naturales "Bernardino Rivadavia”, Paleontologia, 2(1):1-30.

Milani, E.J. 1997. Evolução tectonoestratigráfica da Bacia do Paraná e seu relacionamento com a geodinâmica fanerozóica do Gondwana sul-oriental. Programa de Pós-graduação em Geociências, Universidade Federal do Rio Grande do Sul, Tese de Doutoramento, $167 \mathrm{p}$.

Milani, E.J. \& Zalán, P.V. 1999. An outline of the geology and petroleum systems of the Paleozoic interior basins of South America. Episodes, 22:199-205.

Ottone, E.G. 1996. Devonian palynomorphs from the Los Monos Formation, Tarija Basin, Argentina. Palynology, 20:105-155.

Paim, P.S.G.; Piccoli, A.E.M.; Sarturi, J.A.D.; Munaro, P.; Holz, M \& Granioff, W. 1983. Evolução paleogeográfica do Supergrupo Tubarão na área de Mariana Pimentel-Faxinal, Guaíba, RS. In: SIMPÓSIO SUL-BRASILEIRO DE GEOLOGIA, 1, 1983. Atas, Porto Alegre, SBG, p. 121-134. 
Pasqualini, M.; Cunha, A.S.; Guerra-Sommer, M. \& Piccoli, A.E.M. 1986. Análise paleoecológica de sequiências paleoflorísticas na área de Mariana Pimentel-Guaíba, RS. In: CONGRESSO BRASILEIRO DE GEOLOGIA, 34, 1986. Anais, Goiânia, SBG, 1:556-569.

Piccoli, A.E.M.; Paim, P.S.G.; Sartori, J.A.D.; Holz, M.; Munaro, P. \& Granitoff, W. 1983. Geologia do Supergrupo Tubarão na região de Mariana Pimentel-Faxianal, Guaíba, RS. In: SIMPÓSIO SUL-BRASILEIRO DE GEOLOGIA, 1, 1983. Atas, Porto Alegre, SBG, p. 125-139.

Retallack, G.J., 1980. Late Carboniferous to Middle Triassic megafossil floras from the Sydney Basin. In: C. Herbert $\&$ R. Helby (eds.) A guide to the Sydney Basin, Bulletin Geological Survey of New South Wales, 26: 384-430.

Santos, R.V.; Souza, P.A.; Alvarenga, C.J.S.; Dantas, E.L.; Pimentel, M.M.; Oliveira, C.G. \& Araújo, L.M. 2006. Shrimp U-PB Zircon dating and palynology of bentonitic layers from the Permian Irati Formation: stratigraphic implications for Southwestern Gondwana. Gondwana Research, 9:456-463.

Silveira, A.S. 2000. Estratigrafia de seqüências e evolução paleoambiental da sucessão permiana (Sakmariano-EoKazaniano) da bacia do Paraná, entre Rio Pardo e Mariana Pimentel (RS). Programa de Pós-Graduação em Geologia, Universidade do Vale do Rio dos Sinos, Dissertação de Mestrado, 132 p.

Souza, P.A. 2000. Palinobioestratigrafia do Subgrupo Itararé, Carbonífero/Permiano, na porção nordeste da Bacia do Paraná (SP/PR, Brasil). Programa de Pós-graduação em Geologia Sedimentar, Universidade de São Paulo, Tese de Doutoramento, 199 p.

Souza, P.A. 2003. New palynological data of the Itararé Subgroup from the Buri coal (Late Carboniferous, Paraná Basin), São Paulo State, Brazil. Revista Brasileira de Paleontologia, 5:49-58.

Souza, P.A. 2006. Late Carboniferous palynostratigraphy of the Itararé Subgroup, northeastern Paraná Basin, Brazil. Review of Palaeobotany and Palynology, 138:9-29.

Souza, P.A. \& Callegari, L.M. 2004. An Early Permian palynoflora from the Itararé Subgroup, Paraná Basin, Brazil. Revista Española de Micropaleontología, 36(3):439-450.

Souza, P.A. \& Marques-Toigo, M. 2003. An overview on the palinoestratigraphy of the Upper Paleozoic strata of the Brazilian Paraná Basin. Revista del Museo Argentino de Ciencias Naturales, 5(2):205-214.

Souza, P.A. \& Marques-Toigo, M. 2005. Progress on the palinoestratigraphy of the Permian strata in Rio Grande do Sul State, Paraná Basin, Brasil. Anais da Academia Brasileira de Ciências, 77(2):353-365.

Tiwari, R.S. \& Moiz, A.A. 1971. Palynological study of Lower Gondwana (Permian) coals from Godavari Basin, Índia. I One some new miospore genera. Paleobotanist, 19(1):95-104.

Vieira, C.E.L. \& Iannuzzi, R. 2000. Presença de Pecopteris e Asterotheca no afloramento Morro do Papaléo, município de Mariana Pimentel, RS (Formação Rio Bonito, Eopermiano da bacia do Paraná). Pesquisas, 27(2):49-64.

Ybert, J-P. 1975. Étude des miospores du Bassin Houiller de Candiota-Hulha Negra, Rio Grande do Sul, Brésil. Pesquisas, 5:181-226.
Apêndice 1. Base nomenclatural dos táxons identificados.

Appendix 1. Nomenclatural basis of identified taxa. ESPOROS

Brevitriletes levis (Balme \& Hennelly) Bharadwaj \& Salujha 1964 (Figura 4C)

Calamospora hartungiana Schopf in Schopf, Wilson \& Bentall 1944

(Figura 4A)

Cirratriradites sp. (Figura 4M)

Convolutispora candiotensis Ybert 1975 (Figura 4J)

Cristatisporites irradiatus (Dias-Fabrício) Picarelli \& Dias-Fabrício 1990

Cristatisporites microvacuolatus Dias-Fabrício emend. Picarelli \&

Dias-Fabrício 1990 (Figura 4U)

Cristatisporites morungavensis Dias-Fabrício emend. Picarelli \&

Dias-Fabrício 1990 (Figura 4T)

Cyclogranisporites sp. (Figura 4I)

Granulatisporites triconvexus Staplin 1960 (Figura 4D)

Horriditriletes gondwanensis (Tiwari \& Moiz) Foster 1975 (Figura 4E) Horriditriletes ramosus (Balme \& Hennelly) Bharadwaj \& Salujha 1964 (Figura 4H)

Horriditriletes superbus (Foster) Césari, Archangelsky \& Seoane 1995 (Figura 4G)

Horriditriletes uruguaiensis (Marques-Toigo) Archangelsky \& Gamerro 1979 (Figura 4F)

Kraeuselisporites volkheimerii Azcuy 1975 (Figura 4Q)

Lundbladispora braziliensis (Pant \& Srivastava) Marques-Toigo \& Pons emend. Marques-Toigo \& Picarelli 1984 (Figura 4O)

Lundbladispora riobonitensis Marques-Toigo \& Picarelli 1984 (Figura 4N, P)

Punctatisporites gretensis Balme \& Hennelly 1956 (Figura 4B)

Reticulatisporites pseudopalliatus Staplin 1960 (Figura 4L)

Vallatisporites cilliaris (Lüber) Sullivan 1964 (Figura 4S)

Vallatisporites splendens Staplin \& Jansonius 1964 (Figura 4R)

\section{GRÃOS DE PÓLEN}

Caheniasaccites flavatus Bose \& Kar emend. Azcuy \& Di Pasquo 2000 Cannanoropolis janakii Potonié \& Sah 1960 (Figura 5A)

Cycadopites sp. (Figura 5J)

Divarisaccus stringoplicatus Ottone 1991 (Figura 5B)

Illinites unicus Kosanke emend. Jansonius \& Hills 1976

Limitisporites sp. (Figura 5F)

Peppersites sp. (Figura 5C)

Protohaploxypinus goraiensis (Potonié \& Lele) Hart 1964

Protohaploxypinus limpidus (Balme \& Hennelly) Balme \& Playford 1967 (Figura 5G)

Striomonosaccites sp. (Figura 5E)

Vesicaspora sp. (Figura 5D)

Vittatina vittifera (Lüber \& Valtz) Samoilovich 1953 (Figura 5I)

Vittativa costabilis Wilson 1962 (Figura $5 \mathrm{H}$ )

ALGAS

Brazilea helby forma gregata Foster 1979 (Figura 5N)

Brazilea scissa (Balme \& Hennelly) Foster 1975 (Figura 5M)

Leiosphaeridia sp. (Figura 5P)

Quadrisporites horridus (Hennelly) Potonié \& Lele 1961 (Figura 5L)

Tetraporina sp. (Figura 50)

FUNGOS

Portalites gondwanensis Nahuys, Alpern \& Ybert 1968 (Figura 5Q) Esporos de fungos indeterminados (Figuras $5 \mathrm{R}, \mathrm{S}$ ) 